\title{
A EDUCAÇÃO DE JOVENS E ADULTOS E O ENSINO DE CIÊNCIAS NATURAIS: CONTRIBUIÇÕES DA UTILIZAÇÃO DOS CONCEITOS UNIFICADORES
}

PRODUÇÃO TÉCNICA 


\section{LISTA DE FIGURAS}

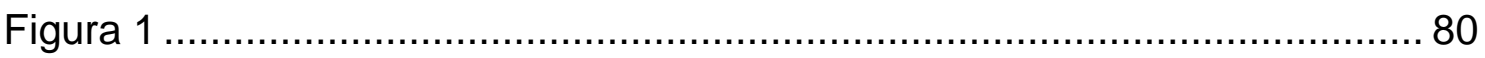

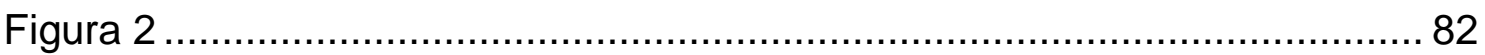

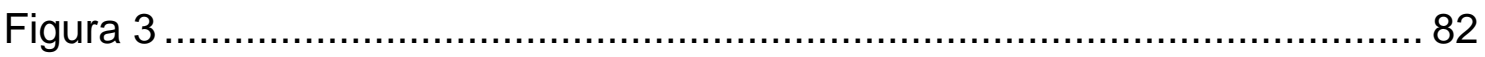

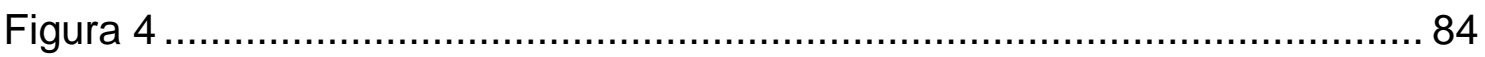

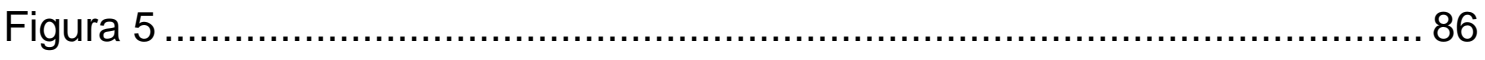

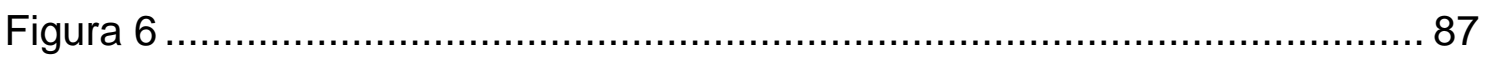

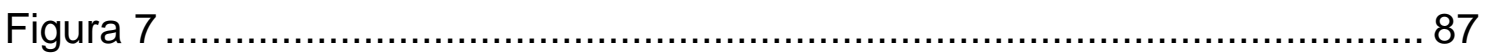




\section{SUMÁRIO}

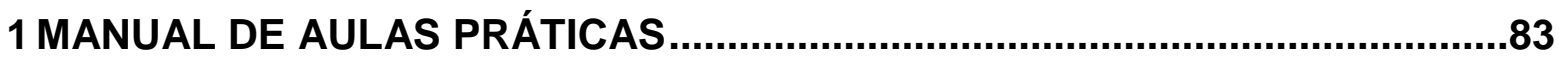

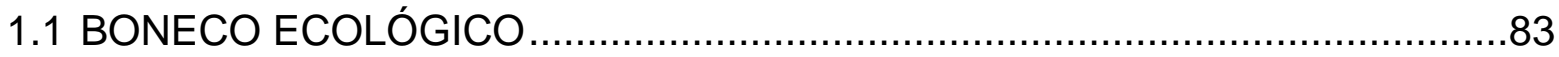

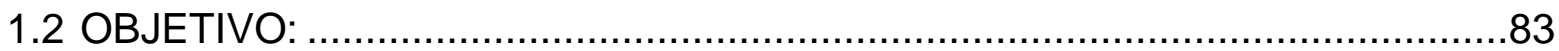

1.3 MATERIAIS:

1.4 DESENVOLVIMENTO:

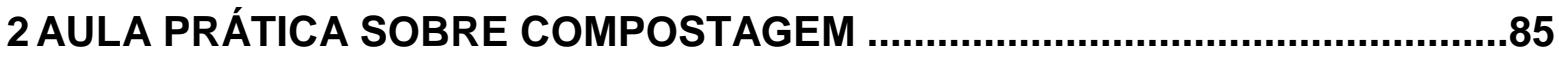

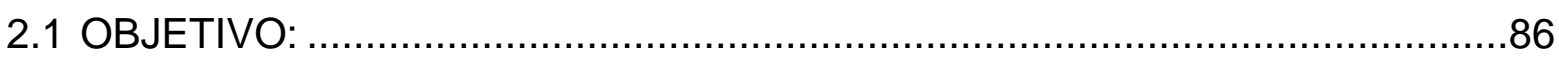

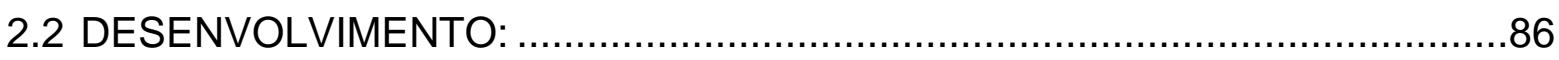

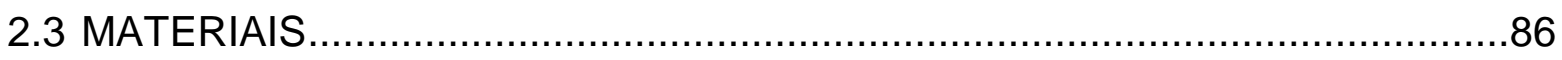

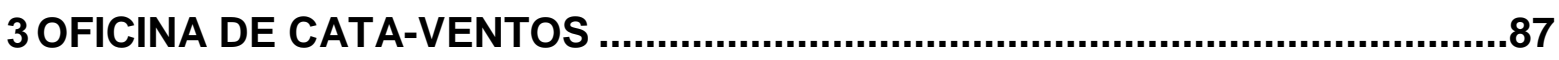

3.1 OBJETIVOS:

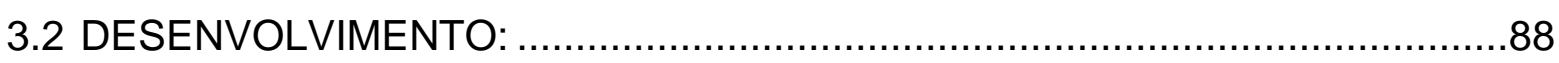

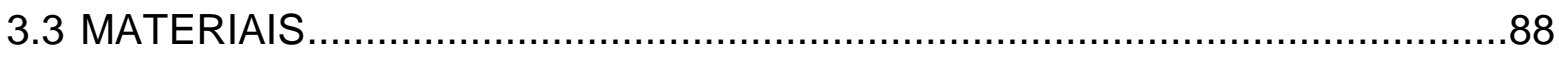

4 AULA PRÁTICA SOBRE O EFEITO ESTUFA ............................................889

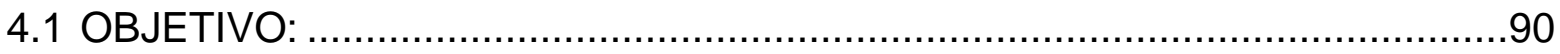

4.2 MATERIAIS:

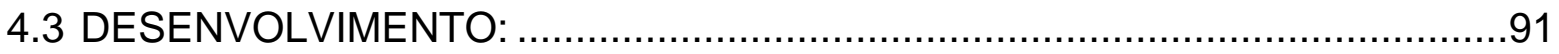

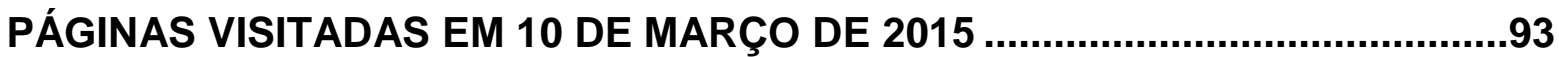




\section{MANUAL DE AULAS PRÁTICAS}

\subsection{BONECO ECOLÓGICO}

As plantas utilizam a energia proveniente do sol para realizar a fotossíntese que é um processo em que existe conversão de energia luminosa em energia elétrica e, desta última, em energia química As reações da fotossíntese ocorrem dentro de organelas celulares denominadas cloroplastos, a luz é capturada nos cloroplastos por um grupo de pigmentos, a clorofila, que é o principal pigmento envolvido na fotossíntese, absorvendo energia luminosa. Quando os pigmentos absorvem luz, os elétrons são empurrados para um nível de energia superior que, na fotossíntese, causam uma reação química.

A fotossíntese tem o papel de manter a organização e a atividade característica dos seres vivos, ao tomar a energia resultante das reações termonucleares que ocorrem no Sol e incorporá-la aos sistemas biológicos. A fotossíntese permite, portanto, que se crie um fluxo contínuo de energia proveniente do Sol através dos sistemas vivos.

Os vegetais são autótrofos, fixando a energia solar nas ligações químicas formadas durante a síntese da glicose. Durante a fotossíntese, percebe-se que os seres autótrofos são capazes de suprir matéria e energia para suas próprias necessidades, desde que as condições ambientais sejam adequadas.

Com a atividade do Boneco Ecológico os alunos podem perceber a importância da luz do Sol para o processo de fotossíntese, vivenciando o desenvolvimento da planta nesse processo.

\subsection{OBJETIVO:}

A partir dessa atividade, o professor pode abordar temas como a importância da água para os seres vivos, a germinação da semente, fotossíntese e a importância da luz para os seres vivos e como as atividades humanas podem interferir no meio ambiente. 


\subsection{MATERIAIS:}

- Meia calça fina usada;

- Serragem;

- Alpiste ou painço;

- Cola;

- Canetas hidrocor;

- Tintas;

- Ligas de borracha;

- Olhinhos de plástico ou botões de camisa;

- Potes de iogurte vazios.

\subsection{DESENVOLVIMENTO:}

Corte uma perna da meia calça e coloque alpiste, completando com a serragem. Quando terminar de encher amarre e corte o que sobrar:

- Comece a modelar o bonequinho em forma de bola;

- Com as ligas de borracha, puxe um pouco a meia e amarre, fazendo o nariz do bonequinho;

- Em seguida, cole os olhinhos ou botões e faça a boca do bonequinho, montando-o ao gosto do aluno.

- Os potinhos de iogurte servirão como base para os bonequinhos para que, quando regados, possam reter a água. Esses potinhos podem ser decorados de acordo com o gosto de cada aluno.

- Depois de pronto, o bonequinho deve ser molhado todos os dias para que as sementinhas germinem, dando origem aos cabelinhos dos bonecos.

É importante que cada aluno tenha seu próprio boneco. É interessante que os alunos elaborem um diário relatando as fases de seus bonecos, como: em quanto tempo o cabelinho começou a crescer; quantas vezes o cabelo do bonequinho precisou ser cortado; se foi regado todos os dias ou não; quantos centímetros o cabelinho cresceu antes da primeira poda, etc. 
É uma atividade interessante que desperta a consciência dos alunos para a ecologia, fotossíntese e germinação das sementes, além de dar-lhes a oportunidade de cuidar de um ser vivo. Depois de algumas semanas, o professor pode pedir para que os alunos levem os bonequinhos para fazer uma exposição, juntamente com os seus relatos sobre o referido desenvolvimento.

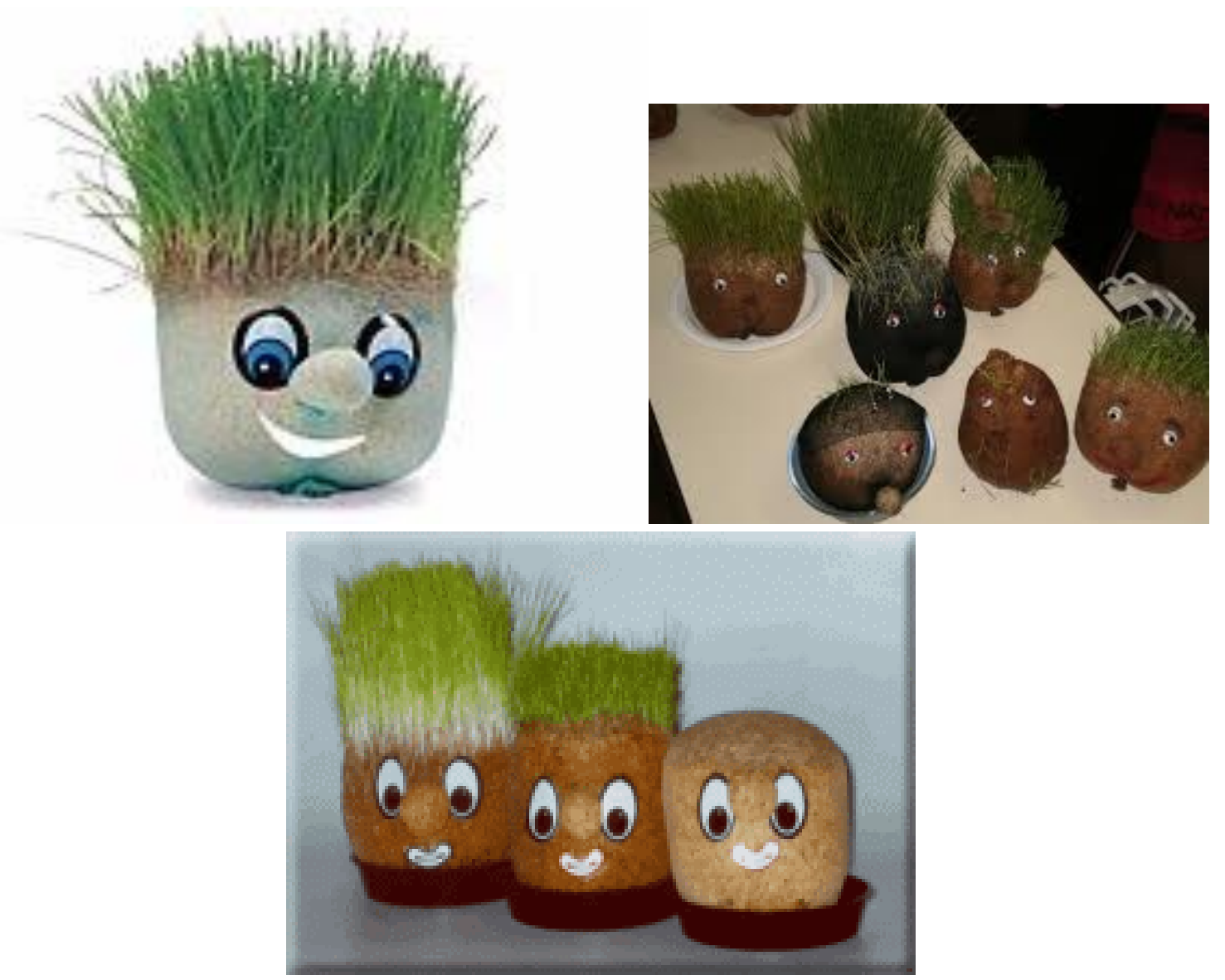

Figura 1

\section{AULA PRÁTICA SOBRE COMPOSTAGEM}

A compostagem é um processo utilizado na agricultura há muito tempo, em que restos de origem animal ou vegetal são misturados ao solo, melhorando suas capacidades físicas e químicas, objetivando uma melhor produção. É um processo biológico em que os microrganismos transformam a matéria orgânica, como o estrume, as folhas, papéis e restos de comida, num material semelhante ao solo, a que se chama composto, e que pode ser utilizado como adubo. $O$ composto deve ter 
uma temperatura morna, sinal de que as reações químicas estão acontecendo, caso esteja muito fria não chega a ser um problema, no entanto, a decomposição total será mais lenta.

\subsection{OBJETIVO:}

- Identificar a problemática do lixo.

- Analisar a situação do lixo no Brasil.

- Resgatar as cores utilizadas na coleta seletiva.

- Aprender que o lixo orgânico pode ser decomposto, gerando adubo e que esse processo envolve temperatura - Conhecer a importância do ciclo de nutrientes.

- Conhecer o processo de compostagem e suas vantagens.

- Estabelecer a relação entre a compostagem e sua importância para o ambiente, despertando a consciência ecológica nos alunos.

\subsection{MATERIAIS}

- Terra

- Garrafa pet

- Resíduos orgânicos: restos de alimentos, cascas de frutas, de ovos, de vegetais.

- Borra de café

- Restos de jardinagem (grama, folhas, flores e arbustos)

- Palha e Serragem

\subsection{DESENVOLVIMENTO:}

Em uma garrafa pet você deve fazer furos ao redor, depois deposite o lixo mais "úmido" por cima da terra; se possível cubra com um pouco de folhagens, finalize com uma boa camada de folhas secas; cubra com serragem e borra de café para evitar o mau cheiro. Se você fez tudo direitinho, depois de um mês já não será possível identificar nenhum tipo de lixo ou restos vegetais. O 
aspecto estará bastante homogêneo, com exceção de galhos, espigas de milho ou caroços muito grandes.

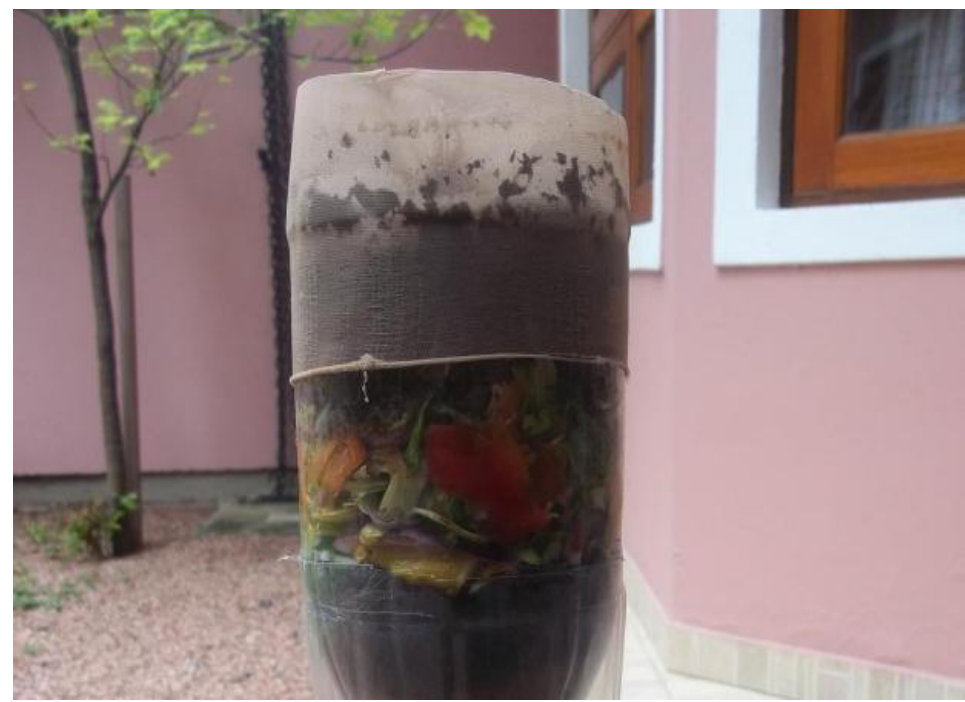

Figura 2

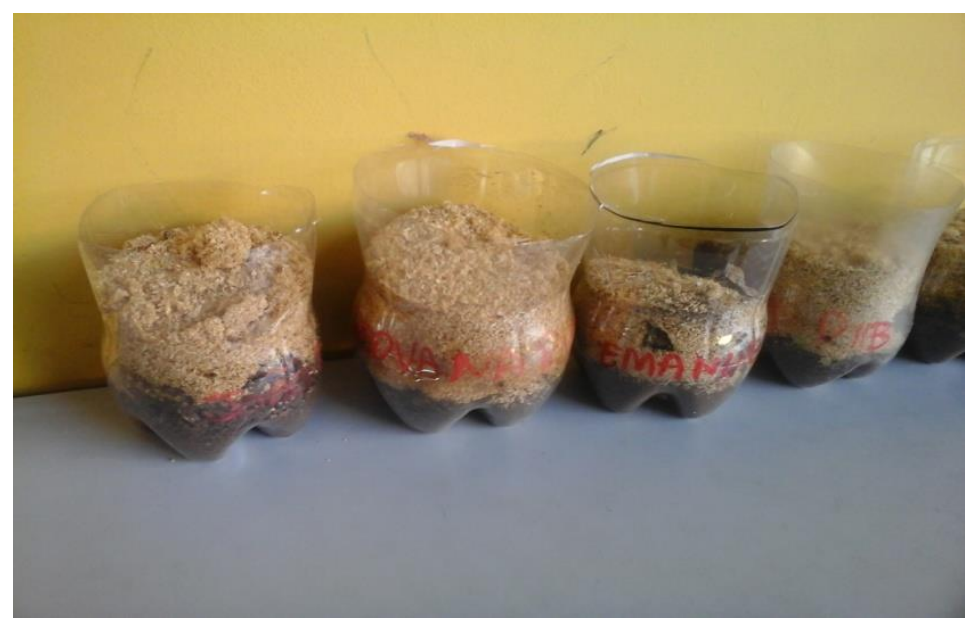

Figura 3

\section{OFICINA DE CATA-VENTOS}

Energia eólica é aquela gerada pelo vento. Desde a antiguidade este tipo de energia é utilizado pelo homem, principalmente nas embarcações e moinhos. Atualmente, a energia eólica, embora pouco utilizada, é considerada uma importante fonte de energia por se tratar de uma fonte limpa (não gera poluição e não agride o meio ambiente). 
A energia eólica é uma forma indireta de obtenção de energia do sol, uma vez que os ventos são gerados pelo aquecimento desigual da superfície da Terra pelos raios solares. Em outros termos, a energia eólica é a energia do movimento (cinética) das correntes de ar que circulam na atmosfera. A energia eólica é uma forma de obtenção de energia de fontes totalmente renováveis e limpas, não produz qualquer tipo de poluente. Sendo por isso, umas das principais apostas no campo das fontes renováveis de energia.

\subsection{OBJETIVOS:}

- Relacionar os cata-ventos ao aproveitamento da energia eólica em aplicações mais engenhosas, como a moenda (os moinhos de vento), o bombeamento de água, ou mais modernamente, para gerar energia elétrica, como os aerogeradores.

- Identificar a energia eólica como a energia do movimento das correntes de ar.

\subsection{MATERIAIS}

- Papel com estampa dupla face ou outro papel de sua preferência;

- Vareta de pipa (papagaio, maranhão) ou palito de churrasco;

- Alfinete;

- Régua, lápis, tesoura;

- Cola quente.

\subsection{DESENVOLVIMENTO:}

1. Corte um quadrado de papel de $20 \mathrm{~cm} \times 20 \mathrm{~cm}$ e trace duas diagonais com uma régua;

2. Faça 4 cortes de $8,5 \mathrm{~cm}$ no papel, começando a cortar pelas pontas;

3. Cole uma ponta do papel ao centro com cola quente e, em seguida, cole as outras 3 pontas para que o papel fique com forma de cata-vento. Use pouca cola;

4. Passe cola na flor de papel recortada com cortador e cole bem no centro para arrematar. Se não tiver cortador pode cortar qualquer forma 
manualmente. Pode ser um círculo, um coração ou outra forma que você gostar.

5. Martele o alfinete ou tachinha $1 \mathrm{~cm}$ abaixo da ponta da vareta e retire-a. Dica: Para não furar a mesa, coloque a ponta da vareta em cima de uma borracha e o restante da vareta em cima de uma revista;

6. Coloque o cata-vento sobre uma borracha (aqui usamos um chinelo) e martele o alfinete no centro;

7. Vire o cata-vento de costas e coloque o alfinete no furo que foi feito na vareta;

8. Corte a ponta do alfinete com alicate;

Dica importante: Para o cata-vento girar é preciso que tenha espaço entre a cabeça do alfinete e a vareta. Se o alfinete ficar muito justo, o cata-vento trava;

9. Arremate as costas da vareta colando um pedacinho de papel sobre o furo, com cola quente.
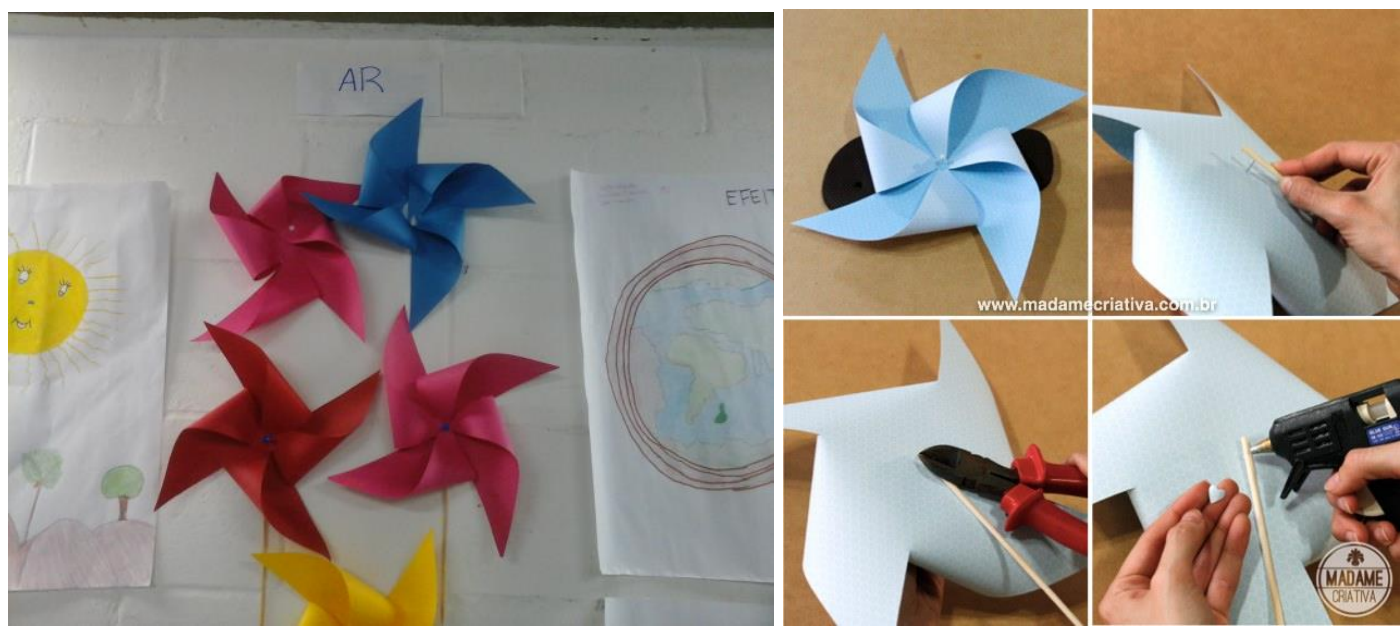

Figura 4

\section{AULA PRÁTICA SOBRE O EFEITO ESTUFA}

O efeito estufa é um fenômeno natural que ocorre em nosso planeta, a fim de manter sua temperatura sempre constante e adequada para a vida na Terra. Se não existisse esse fenômeno, a temperatura do nosso planeta ficaria muito baixa e não existiria vida e nem água na forma líquida. 
O grande problema do efeito estufa é que, no último século, as emissões de gases produzidos pelas atividades humanas, como gás carbônico, metano e óxido nitroso, aumentaram muito, fazendo com que a temperatura na Terra se elevasse, prejudicando o clima do planeta. Muitos estudiosos preveem inúmeros desastres se a emissão de gases aumentar na mesma velocidade dos últimos anos. Dentre essas consequências, podemos citar algumas, como:

- O derretimento das calotas polares levará ao aumento do nível do mar e, em consequência disso, ocasionarão inundações nas costas dos continentes, com grande risco de desaparecimento de cidades litorâneas;

- Alterações nas correntes litorâneas podem afetar a distribuição de calor na Terra;

- Regiões férteis podem se tornar desertos;

- Como consequência das variações climáticas, tempestades violentas podem ocorrer;

- O superaquecimento intensifica a proliferação de insetos prejudiciais à saúde humana.

\subsection{OBJETIVO:}

- Reconhecer a relação entre o efeito estufa e a temperatura do planeta Terra.

\subsection{MATERIAIS:}

A colocação da lista de materiais antes do desenvolvimento torna mais clara a compreensão do mesmo.

- Dois copos plásticos;

- Papel alumínio;

- Tesoura;

- Água;

- Caixa de sapato;

- Filme plástico. 


\subsection{DESENVOLVIMENTO:}

Forre o interior da caixa com papel alumínio (fundo e borda), depois coloque um dos copos de água dentro da caixa. Tampe a caixa com papel filme, então coloque o segundo copo com água e a caixa sob a luz de uma lâmpada acesa ou sob a luz do sol. Após 10 minutos abra a caixa e sinta com o dedo qual dos dois copos está com a água mais quente. O professor deverá explicar aos alunos que ao iluminar a caixa a luz passa pelo filme e se transforma em calor ao atingir a superfície interna. $O$ ar aquece e não pode sair da caixa por causa do filme plástico, aumentando assim, a temperatura interna da caixa. Por esse motivo a água que está no copo dentro da caixa fica mais quente que a água que está fora da caixa. $O$ mesmo ocorre na atmosfera, onde os gases do efeito estufa, assim como o filme plástico na caixa, impedem que o calor na forma de radiação infravermelha volte para o espaço.

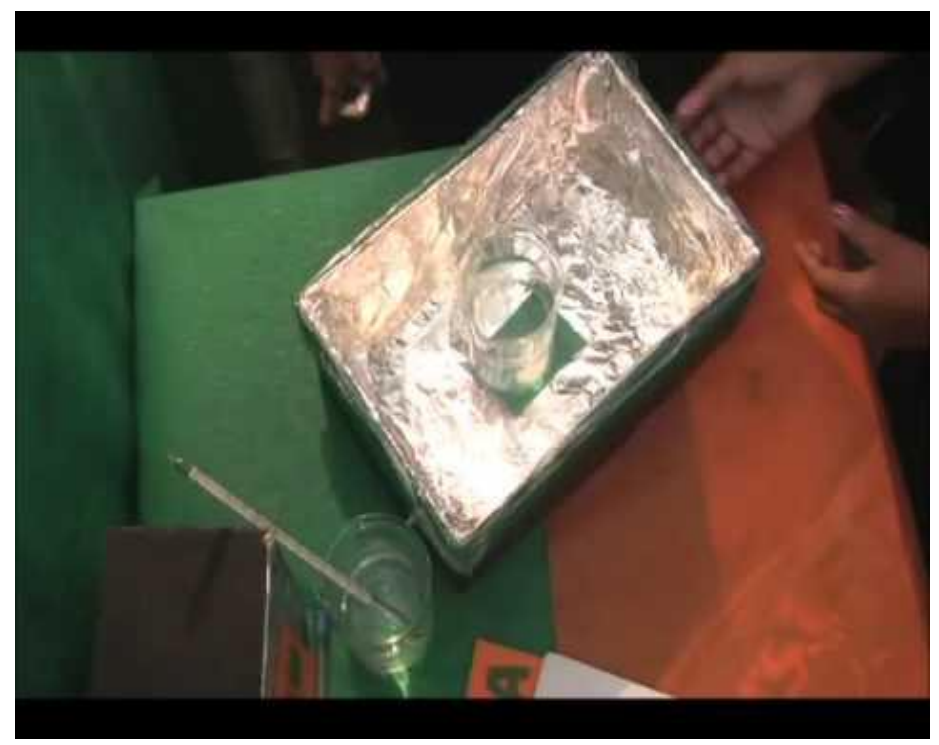

Figura 5 


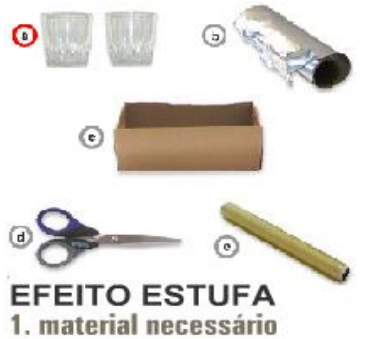

a) dois copos com água;

b) papel aluminio;

c) caixa grande de sapatos:

d) tesoura;

e) filme plástico;

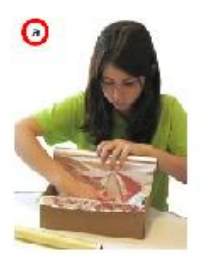

2. passo a passo

a) forre o interior da caixa com o papel alumínio;

b) coloque um dos copos com água dentro da caixa;

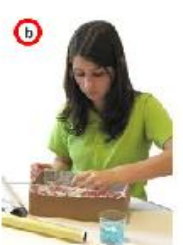

$\odot$
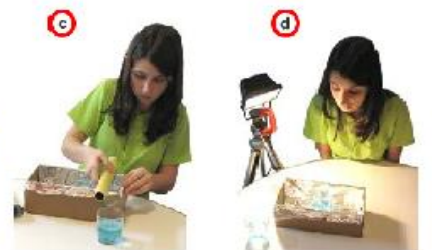

3. passo a passo

c) tampe a caixa com o filme plástico; d) ccloque o segundo sopo e a caixa soo ccloque o segundo 0000 e a caixa soo
luz do Sol ou sob a luz de uma lámpada acessa.

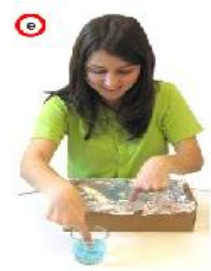

4. passo a passo

e) após dez minutos a bre a caixa e sinte com z dedo qual dos do is capcs esté com a agua mais quente;
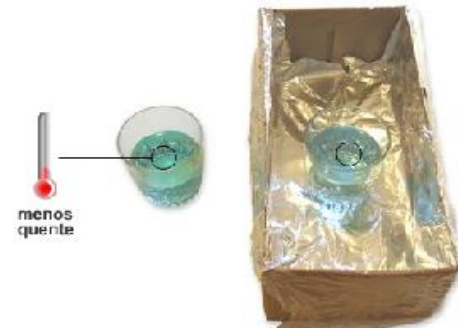

\section{0 que acontece}

Ao iluminar a caixa a luz passa pelo filme e

se transforma em calor ao atingir a

superficie interna. $\mathrm{O}$ ar se aquece e nâo

pode sair da caixa por causa do filme

plástico, aumentando assim a temperatura

interna da caixa.

Por esse motivo, a água do copo que está

dentro da caixa fica mais quente que a

água do copo que está fora.

\section{Figura 6}

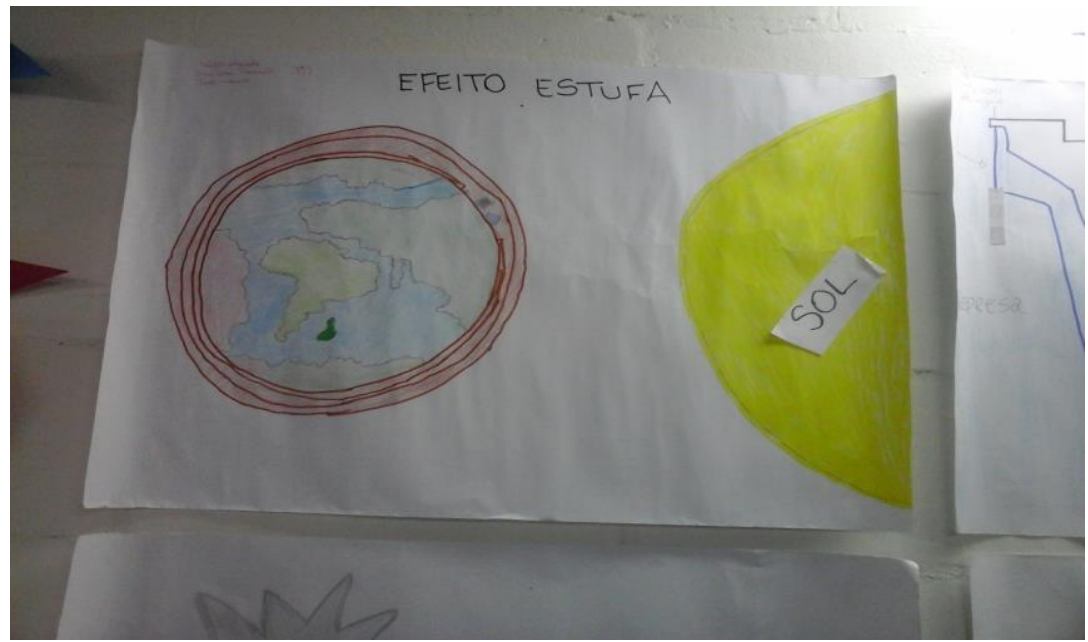

Figura 7 
A energia eólica no Brasil e no mundo | Plano de Aula...

Revista escola.abril.com.br/.../energia-eolica-brasil-mundo-515970.shtml

Como fazer um cata-vento - Dicas - Poupedi Sicredi

https://www.poupedisicredi.com.br/dicas/como-fazer-um-cata-vento

Estudantes realizam experimento para explicar efeito estufa... www.youtube.com/watch?v=R41TI0QmRnU

18 abr. 2011 - Vídeo enviado por Canal PCHAE

\section{Simulador do Efeito Estufa}

www.cienciamao.usp.br/tudo/exibir.php?midia=ICNs\&cod...

AULA PRÁTICA - COMPOSTAGEM - Colégio Agrícola...

www.cpmcagricola.seed.pr.gov.br/modules/noticias/article.php?storyid..

Boneco Ecológico - Atividades práticas para o Ensino de... praticandociencias.blogspot.com/2008/10/boneco-ecolgico.htm

Confeccionando um boneco ecológico - Educador - Brasil. educador.brasilescola.com > Estratégias de Ensino > Biologia 